University of Nebraska - Lincoln

DigitalCommons@University of Nebraska - Lincoln

USDA National Wildlife Research Center - Staff Publications
U.S. Department of Agriculture: Animal and Plant Health Inspection Service

2011

\title{
Who hits and hoots at whom? Potential for interference competition between barred and northern spotted owls
}

Nicholas J. Van Lanen

Colorado State University - Fort Collins, njvanlanen@gmail.com

Alan B. Franklin

USDA-APHIS-WS National Wildlife Research Center, alan.b.franklin@aphis.usda.gov

Kathryn P. Huyvaert

Colorado State University - Fort Collins, Kate.Huyvaert@ColoState.edu

Raoul F. Reiser II

Colorado State University - Fort Collins, rfreiser@cahs.colostate.edu

Peter C. Carlson

Colorado State University - Fort Collins, pcarlson@colostate.edu

Follow this and additional works at: https://digitalcommons.unl.edu/icwdm_usdanwrc

Van Lanen, Nicholas J.; Franklin, Alan B.; Huyvaert, Kathryn P.; Reiser, Raoul F. Il; and Carlson, Peter C., "Who hits and hoots at whom? Potential for interference competition between barred and northern spotted owls" (2011). USDA National Wildlife Research Center - Staff Publications. 1332.

https://digitalcommons.unl.edu/icwdm_usdanwrc/1332

This Article is brought to you for free and open access by the U.S. Department of Agriculture: Animal and Plant Health Inspection Service at DigitalCommons@University of Nebraska - Lincoln. It has been accepted for inclusion in USDA National Wildlife Research Center - Staff Publications by an authorized administrator of DigitalCommons@University of Nebraska - Lincoln. 


\title{
Who hits and hoots at whom? Potential for interference competition between barred and northern spotted owls
}

\author{
Nicholas J. Van Lanen ${ }^{\mathrm{a}, *}$, Alan B. Franklin ${ }^{\mathrm{b}}$, Kathryn P. Huyvaert ${ }^{\text {a }}$, Raoul F. Reiser II ${ }^{\mathrm{c}}$, Peter C. Carlson ${ }^{\mathrm{d}}$ \\ ${ }^{a}$ Department of Fish, Wildlife, and Conservation Biology, Colorado State University, 1474 Campus Delivery, Fort Collins, CO 80523, USA \\ ${ }^{\mathrm{b}}$ United States Department of Agriculture, APHIS/WS National Wildlife Research Center, 4101 LaPorte Avenue, Fort Collins, CO 80521, USA \\ ${ }^{\mathrm{c}}$ Department of Health and Exercise Science, Colorado State University, 1582 Campus Delivery, Fort Collins, CO 80523, USA \\ ${ }^{\mathrm{d}}$ Colorado Cooperative Fish and Wildlife Research Unit, Colorado State University, 1484 Campus Delivery, Fort Collins, CO 80523, USA
}

\section{A R T I C L E I N F O}

\section{Article history:}

Received 13 March 2011

Received in revised form 16 May 2011

Accepted 20 May 2011

Available online 12 June 2011

\section{Keywords:}

Competition

Invasive species

Barred owl

Northern spotted owl

Interference

Exclusion

\begin{abstract}
A B S T R A C T
The northern spotted owl (Strix occidentalis caurina) is a controversial species in the Pacific Northwest that is listed as threatened under the Endangered Species Act. The barred owl (Strix varia), a species historically restricted to eastern North America, has recently expanded its range to completely overlap that of the northern spotted owl. Recent evidence suggests that barred owls may compete with northern spotted owls and may be one cause for recent declines in some northern spotted owl populations. Our focus was to examine whether barred owls have the potential to competitively exclude northern spotted owls from their territories through interference competition. We used a playback experiment to quantify aggressive vocal and physical behavior of barred and northern spotted owls during territorial defense. Experimental trials consisted of displaying northern spotted or barred owl taxidermy mounts, and broadcasting recorded vocalizations of the corresponding species, in both barred and northern spotted owl territories. The frequency of interspecific interactions was lower compared to intraspecific interactions between northern spotted owls alone. However, barred owls responded with higher levels of vocal and physical aggression than did northern spotted owls when agonistic interspecific interactions occurred. Our results suggest that barred owls are likely to assume the dominant role during interspecific interactions with northern spotted owls. Thus, interference competition is a plausible mechanism by which barred owls could contribute to observed population declines of northern spotted owls in areas where the species co-occur.
\end{abstract}

(c) 2011 Elsevier Ltd. All rights reserved.

\section{Introduction}

Mitigating threats to populations of northern spotted owls (Strix occidentalis caurina) has been the focus of intense study over the last 40 years. Observed population declines likely resulting from habitat loss led to the official listing of the northern spotted owl as a threatened species in 1990 (US Fish and Wildlife Service, 1990) and subsequent conservation efforts focused on protecting older forest that was considered suitable northern spotted owl habitat. Northern spotted owl populations have continued to decline despite adoption of the Northwest Forest Plan in 1994, which called for stricter regulation of timber harvest throughout the northern spotted owl's range (Anthony et al., 2006; USDA Forest Service and BLM, 1994). Competition between northern spotted

\footnotetext{
* Corresponding author. Present address: Rocky Mountain Bird Observatory, 230 Cherry St., Fort Collins, CO 80521, USA. Tel.: +1 970692 1100; fax: +1 9704721707.

E-mail addresses: njvanlanen@gmail.com (N.J. Van Lanen), alan.b.franklin@ aphis.usda.gov (A.B. Franklin), Kate.Huyvaert@colostate.edu (K.P. Huyvaert), rfreiser@cahs.colostate.edu (R.F. Reiser), pcarlson@colostate.edu (P.C. Carlson).
}

and barred owls (Strix varia) has been identified as another important potential threat to northern spotted owl populations (Anthony et al., 2006; Buchanan et al., 2007; Gutiérrez et al., 2007; Hamer et al., 1994; Kelly et al., 2003; Taylor and Forsman, 1976).

Historically, the distribution of barred owls was restricted to the eastern portion of the United States. However, the species' range has expanded westward over the past 50 years and now completely overlaps that of the northern spotted owl (Dark et al., 1998; Kelly et al., 2003; Livezey, 2009). Rapidly increasing barred owl populations in the western US, coupled with continued northern spotted owl population declines, suggests that competition with barred owls may threaten remaining northern spotted owl populations. Over the past decade, studies investigating the potential impact of barred owls on northern spotted owl populations found that colonization and extinction rates, territory occupancy, and survival of northern spotted owls may be negatively affected by the presence of barred owls (Anthony et al., 2006; Kelly et al., 2003; Olson et al., 2005).

Interspecific interference competition during territorial interactions could explain the witnessed impacts on northern spotted owls 
because of observed interactions between the two species (Dunbar et al., 1991; Herter and Hicks, 2000), some of which may represent intraguild predation (Leskiw and Gutiérrez, 1998). Intraguild predation occurs when the dominant of two morphologically similar species acts as both competitor and predator (Polis et al., 1989). In these instances, the dominant species benefits by reducing resource competition, reducing risk to offspring, and/or obtaining energetic benefits by consuming competitors (Sergio and Hiraldo, 2008). Several studies demonstrated intraguild predation in raptor communities that include owls (Martínez et al., 2008; Sergio et al., 2003, 2007; Zuberogoitia et al., 2008), supporting the idea that intraguild predation may exist in the northern spotted owl/barred owl system. In the presence of intraguild predation (Polis et al., 1989), the barred owl should fill the role of dominant competitor and predator during interactions with northern spotted owls because barred owls have larger body mass ( $\bar{x}=630$ and $800 \mathrm{~g}$ for males and females, respectively; Mazur and James, 2000) than northern spotted owls ( $\bar{x}=600$ and $654 \mathrm{~g}$; Gutiérrez et al., 1995).

To determine whether interference competition is a plausible mechanism by which barred owls can contribute to northern spotted owl population declines, we conducted a series of playback experiments to quantify territorial encounters between the two species. By simulating inter- and intraspecific encounters and quantifying attack responses by territory residents, we addressed whether or not interference competition by barred owls could be a contributing factor to continued northern spotted owl population declines. Specifically, we investigated the Exclusion and Acquiescence Hypotheses where (1) the Exclusion Hypothesis predicts that barred owls actively exclude northern spotted owls through interference competition expressed as frequent vocal aggression and physical attacks with increased capacity to cause injury and (2) the Acquiescence Hypothesis predicts that northern spotted owls defend their territories with less vigorous calling and a reduced number of physical attacks against barred owls than against northern spotted owls.

\section{Methods}

We conducted experiments on four study areas which were concurrently surveyed for northern spotted and barred owls: Redwood National Park (RNP), Green Diamond Resource Company lands (GDRC), Hoopa Tribal lands (HOOPA), and the Willow Creek study area (WCSA, part of the Northwest California demographic study) in Humboldt and Trinity counties in northwestern California (see Anthony et al., 2006). RNP and the majority of GDRC lands are located within $32 \mathrm{~km}$ of the Pacific coast where redwood (Sequioia sempervirens) trees dominate forest over-stories and hardwood understories are predominated by tanoak (Lithocarpus densiflorus), red alder (Alnus rubra), and Pacific madrone (Arbutus menziesii) (Diller and Thome, 1999). Due to the proximity of the coast, these two mesic study sites experience milder temperatures and higher rates of precipitation throughout the year than the HOOPA and WCSA sites (Ting, 1998). The HOOPA and WCSA sites are located approximately $50 \mathrm{~km}$ east of RNP and the GDRC lands. The coniferous forests in these two study areas lack redwood trees and the over-stories of these two areas are dominated by Douglas fir (Pseudotsuga menziesii) mixed with hardwood species (Ting, 1998; Franklin et al., 2000). In general, the RNP and HOOPA sites appeared to have a greater proportion of historic northern spotted owl territories occupied by barred owls than do the WCSA and GDRC sites (Anthony et al., 2006). For example, in 2003 barred owls were detected at approximately $50 \%$ of the historic northern spotted owl territories within RNP (Schmidt, 2004) whereas they were detected at fewer than $20 \%$ of historic northern spotted owl territories on the WCSA site (Franklin et al., 2009).

\subsection{Experimental design}

Using a quasi-experimental design, playback trials were conducted on barred and northern spotted owl territories from midMay through mid-August in 2008 and 2009. Territories were considered the sampling unit and defined as $710 \mathrm{~m}$ radius circles (Franklin et al., 2000) centered on areas where owls had been detected during the current and preceding breeding seasons or areas where owls were determined to be actively breeding during the current field season. This collection of northern spotted and barred owl territories represented two separate sampling frames from which 63 territories for experimentation were randomly drawn each year, without replacement.

Playback trials for each territory were conducted within $100 \mathrm{~m}$ of the most recent daytime detection of territorial males within the current breeding season. If no daytime location was available, trials were conducted within $100 \mathrm{~m}$ of the most recent nighttime detection. We attempted to conduct playback trials on ridges to maximize resident owls detecting the playback and observers detecting vocalizations by the resident owls. Trials were conducted under three treatments consisting of the resident species occupying the territory (barred or northern spotted owl) and a single playback species presented within the resident territory (barred or northern spotted owl). For trials under the first treatment, a northern spotted owl taxidermy mount was presented and vocalizations broadcast in a northern spotted owl territory. This treatment was a local control to provide baseline data on intraspecific competition occurring among northern spotted owls. For trials in the second treatment a barred owl mount and vocalizations were presented in a northern spotted owl territory, and in the third treatment, a northern spotted owl mount and vocalizations were presented in a barred owl territory. To control for seasonal effects on territoriality (Reid et al., 1999; Waldo, 2002), trials for all treatments were assigned evenly across three seasonal periods (20 May-20 June, 21 June-20 July, 21 July-20 August) which corresponded to periods when owls were nesting, fledging young, and when fledged young were becoming independent (Franklin et al., 2000). Due to logistic constraints, actual sampling of treatment groups differed slightly from the targeted sample of seven trials/ treatment/seasonal period (Van Lanen, 2010).

\subsection{Playback procedures}

All trials began 30-60 min after official sunset time (NOAA Earth System Research Laboratory, 2008) because northern spotted and barred owls are most active shortly after sunset but are still near their roost sites (Forsman et al., 1984; Odom and Mennill, 2010). We used taxidermy mounts made from salvaged northern spotted and barred owl carcasses. For each trial, the base of the appropriate taxidermy mount was affixed atop a $1.5 \mathrm{~m}$ tall aluminum pole along with an amplifying speaker oriented to broadcast sound in the direction the mount was facing. Together, the mount and speaker on the pole were, rotated $90^{\circ}$ at 5 min intervals following the start of the playback to broadcast in all directions. Recorded vocalizations were played using a continuous compact disk (CD) recording lasting $60 \mathrm{~min}$, with five periods of intermittent calling separated by approximately 4-min periods of silence. The composition of call types changed throughout the duration of the playback $\mathrm{CD}$ from territorial calls to aggressive territorial calls to simulate an intruder becoming increasingly agitated. Male vocalizations were used in both recordings because males of both species are more likely to vocalize in territorial defense (Forsman et al., 1984; Freeman, 1999). In the event of a response, the time, species, and sex were documented, and resident vocalizations were recorded with an omni-directional microphone. Vocalizations of both northern spotted and barred owls were tabulated and 
classified as either contact, territorial, or aggressive calls (Forsman et al., 1984; McGarigal and Fraser, 1985). The sex of the responding owl was determined by the tone and pitch of the vocal response (Franklin et al., 1996; Odom and Mennill, 2010) in the field and from audio recordings. Intermediate vocalizations that could not be confidently assigned to a particular sex were attributed to an individual of an unknown sex and were excluded from the analyses. Observers used night vision goggles to detect owls that silently approached the model. Some playback trials were truncated $(n=9$, $7 \%$ of trials) because either (1) the responding individuals struck the owl mount and dislodged the head such that it could not be re-attached; the trial was truncated at the time of the strike or (2) neighboring hetero- or conspecifics responded during trials, which were truncated when the neighbor first vocalized because resident responses could no longer be attributed strictly to the playback treatment.

Instances where direct physical contact between a resident owl and the taxidermy mount or when a resident owl flew within $1 \mathrm{~m}$ of the mount with its legs lowered but no physical contact occurred were classified as "attacks." Camcorders equipped with infrared lights were used to record footage of physical responses to the mount and this footage was later reviewed to confirm the nature and timing of attacks. To quantify the risk of head injury due to the blunt force of strikes, accelerations experienced by the head of the owl mount as a result of strikes by resident owls were recorded with a tri-axial analog accelerometer (PCB Piezotronics Model 356M162) that was placed in the head of the taxidermy mounts. A laptop computer powered the accelerometer through a signal conditioner (National Instruments NI USB-9162 with NI 92334 Channel Analogue Input). Acceleration data were recorded using LabView 8.5 Software (National Instruments Corporation) at a rate of 10,000 samples per second when "triggered" by a strike.

\subsection{Data analyses}

Competing biological hypotheses developed a priori were expressed as statistical models where the response variables were detection of any response, aggressive call frequency during responses, whether an attack occurred during a response, and total number of attacks during trials with a response (Table 1). Response variables were tabulated for the male resident only. Binary response variables (detection of a response and whether an attack occurred) were analyzed using logistic regression and continuous response variables were analyzed using generalized linear models
(PROC LOGISTIC and PROC GENMOD, respectively) implemented in SAS 9.1 (SAS Institute, 2003).

Analyses on the frequency of male resident responses to the treatment were conducted on the full set of 126 playback trials. To investigate the magnitude of male residents' responses when agonistic interactions occurred, we used a subset of 79 trials in which a male resident response was detected. Analyses with this subset of data were considered particularly important because trials where no resident response was observed could have resulted from residents not detecting the treatment, observers not detecting a resident response, or the residents not responding. An information-theoretic approach was used for all analyses (Burnham and Anderson, 2002) to select appropriate models for inference. Models resulting in quasi-complete separation in the logistic regression analyses (SAS Institute, 2003) were removed from the model set due to poor model convergence. Models were ranked in each model set using Akaike's Information Criterion for small sample sizes (AICc). Akaike weights were calculated for each model as the probability that a given model in the candidate model set was the best model for inference, given the data and the model set.

A priori models in each model set included the treatment effect (TT) as well as additive effects of covariates (Table 1) and two- and three-way interactions, which were thought to be biologically meaningful. Covariates such as study area and timing within the season (Ganey, 1990; Mazur and James, 2000; Waldo, 2002), lunar cycles (Ganey, 1990), breeding status of the resident pair (determined using methods described by Franklin et al. (1996)), and the duration of occupancy of territories by individuals (Hyman et al., 2004; Sergio et al., 2009) were considered important because of their potential effects on the rate and intensity of owl responses and were included to reduce potential confounding of treatment with other effects. Although the age of individuals may influence territorial aggressiveness, we were unable to include this as a covariate because the ages of individual barred owls were largely unknown throughout the study area. $R^{2}$ and maximum re-scaled $R^{2}$ values were used as measures of the proportion of variance explained by the models for continuous and binary response variables, respectively. For some model sets, additional models were constructed a posteriori, where combinations of additive effects and two-way interactions resulted in low $\triangle \mathrm{AICC}$ values during the a priori analyses.

Effects were estimated for treatments where barred owl residents were presented with the northern spotted owl playback and where northern spotted owl residents were presented with

Table 1

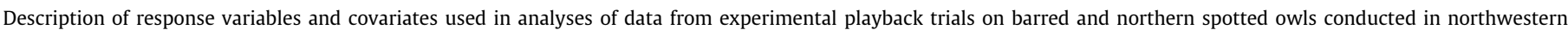
California.

\begin{tabular}{|c|c|c|c|}
\hline Variable & Acronym & Type & Description \\
\hline \multicolumn{4}{|l|}{ Response variables } \\
\hline Male response & - & Binary & Whether a male responded ( 1 ) or did not respond (0) during a trial \\
\hline Male attacks & - & Binary & Whether a male attacked ( 1 ) or did not attack $(0)$ the presented mount during the trial \\
\hline Male aggressive call frequency & - & Continuous & Number of male aggressive calls per minute \\
\hline Total number of male attacks & - & Continuous & Total number of male strikes and swoops during the trial \\
\hline \multicolumn{4}{|l|}{ Covariates } \\
\hline Treatment type & $T T$ & Categorical & Combination of resident and playback species for each trial \\
\hline $\begin{array}{l}\text { Duration of territory } \\
\text { occupancy }\end{array}$ & $T Y$ & Continuous & Known number of years male resident owl was observed on territory \\
\hline Study area & SC & Categorical & Interior versus coastal study areas \\
\hline Adjusted julian date & $A D$ & Continuous & Number of days after May 20 (the date of first trials) \\
\hline Moon phase & $M P$ & Continuous & Visible quarters of the moon at the end of the trial $(1=1 / 4$ moon, $2=1 / 2 \mathrm{moon}, 3=3 / 4$ moon, $4=$ full moon $)$ \\
\hline Truncation code & TC & Categorical & Whether or not the trial was truncated for any reason \\
\hline Year code & $Y C$ & Categorical & 2008 versus 2009 field seasons \\
\hline UTM days & $U D$ & Continuous & Number of days between the last known owl location and the playback trial \\
\hline Reproductive code & $R C$ & Categorical & Whether residents were reproductively active, inactive, or of undetermined status \\
\hline Pair code & $P C$ & Categorical & Whether residents were single, paired, or of undetermined pair status \\
\hline Female presence & $F P$ & Categorical & Whether or not the resident female was detected during the trial \\
\hline
\end{tabular}


the barred owl playback by setting the intercept as the treatment where northern spotted owl residents received the northern spotted owl treatment. Predictions of the Exclusion Hypothesis were assessed by estimating the difference in the parameter estimates for the intercept and the treatment effect where barred owl residents were presented with the northern spotted owl playback treatment. Similarly, the Acquiescence Hypothesis was evaluated by estimating the difference in the parameter estimates for the intercept and the treatment effect where northern spotted owls received the barred owl playback treatment. To account for model selection uncertainty, we model-averaged across all models in a given model set except the intercept-only model. Using these modelaveraged values, we provide unconditional estimates of parameters $(\widehat{\bar{\beta}})$ and 95\% confidence intervals (Burnham and Anderson, 2002).

Using data from the accelerometer, the potential for brain injury resulting from strikes was compared using the Head Index Criterion $(H I C)$, which is typically used in studies investigating human brain trauma (Beckwith et al., 2007; Pfister et al., 2009; Turchi et al., 2004). HIC was calculated over a period of $15 \mathrm{~ms}\left(H_{15}\right)$ (Jackson et al., 2002; Pfister et al., 2009) for all strikes to account for the entire acceleration event recorded by the accelerometer. An $H_{1} C_{15}$ value for each strike was calculated as:

$H I C_{15}=\left[\frac{1}{\left(t_{2}-t_{1}\right)} \int_{t_{1}}^{t_{2}} a(t) d t\right]^{2.5}\left(t_{2}-t_{1}\right)$

where $\left(t_{2}-t_{1}\right)=0.015 \mathrm{~s}$ and $a(t)=$ the magnitude of the resultant three-dimensional acceleration in g's occurring at time $(t)$.

\section{Results}

\subsection{Vocal responses}

We recorded 79 male responses $(n=18$ barred owl responses during 39 trials, $n=61$ northern spotted owl responses during 87 trials) during the 126 playback trials conducted. In the analysis examining whether a response was detected or not, the top-ranked logistic regression model was almost six times more likely than the second-ranked model, and accounted for $28 \%$ of the variation in the data (Table 2). Together, the top two models accounted for all of the Akaike weight, with these two models differing only by inclusion of an interaction in the second-ranked model (Table 2). Both models included whether a female was present during the trial $(F P)$, which was positively associated with male responses $(\hat{\bar{\beta}}=1.02,95 \% \mathrm{CI}=0.52,1.51)$. Based on the 95\% confidence intervals, model-averaged estimates of $T T$ indicated male barred owl residents responded similarly to the northern spotted owl treatment as male northern spotted owls did to the barred owl treatment (Table 3).

When males responded ( $n=79$ trials), the top-ranked generalized linear model for male calling frequency was an a posteriori model, which included adjusted Julian date $(A D)$, female presence (FP) and the interaction of $T T$ with $A D$ (Table 2). This model explained $38 \%$ of the variation in the data (Table 2 ). The $A D$ covariate was incorporated in each of the top seven models (combined Akaike weight $=0.99$ ) and appeared to negatively influence call frequency $(\widehat{\bar{\beta}}=-0.02,95 \% \mathrm{CI}=-0.03,-0.01)$ while the FP covariate was included in three of the top four models (combined Akaike weight $=0.83$ ) and was positively associated with male call frequency $(\hat{\bar{\beta}}=0.55,95 \% \mathrm{CI}=0.08,1.02)$. Given a response, male barred owls called more often when presented with the northern spotted owl treatment than northern spotted owls did when responding to a conspecific (Table 3 ). In contrast, male northern spotted owls called less frequently in response to the barred owl treatment than toward the northern spotted owl treatment (Table 3).

\subsection{Physical attacks}

In the analysis of whether males attacked during responses ( $n=79$ trials), TT and adjusted Julian date $(A D)$ were present in the top two logistic regression models, which had a combined Akaike weight $=0.60$ (Table 2 ) and explained $35 \%$ and $36 \%$ of the variation in the data, respectively. Model-averaged estimates of the effect size of $A D$ suggested that male residents were less likely to attack as the season progressed $(\widehat{\bar{\beta}}=-0.03,95 \% \mathrm{CI}=-0.06$, 0.01 ). Barred owls were more likely to attack the northern spotted owl model and northern spotted owls were less likely to attack the barred owl model than northern spotted owls receiving the northern spotted owl treatment (Table 3).

\section{Table 2}

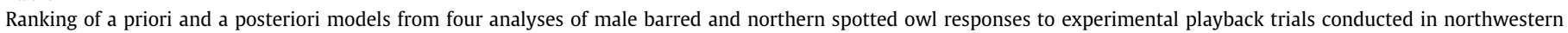
California. Covariates included in the models are described in Table 1 . Only models with Akaike weights $\geqslant 0.05$ are shown for each analysis.

\begin{tabular}{|c|c|c|c|c|}
\hline Model & $R^{2}$ & $K$ & $\Delta \mathrm{AICc}^{\mathrm{a}}$ & Akaike weight $^{\mathrm{b}}$ \\
\hline \multicolumn{5}{|c|}{ General response ( $n=126$ trials) } \\
\hline$T T+F P$ & 0.28 & 4 & 0.00 & 0.85 \\
\hline$T T+F P+T T * F P$ & 0.28 & 6 & 3.53 & 0.15 \\
\hline \multicolumn{5}{|c|}{ Male aggressive call frequency - responses only $(n=79)$} \\
\hline$T T+F P+A D+T T * A D^{c}$ & 0.38 & 8 & 0.00 & 0.73 \\
\hline$T T+A D+T T * A D$ & 0.33 & 7 & 3.58 & 0.12 \\
\hline$T T+F P+A D+F P * A D$ & 0.32 & 7 & 5.19 & 0.05 \\
\hline$T T+R C+F P+A D+R C * A D^{\mathrm{c}}$ & 0.38 & 10 & 5.59 & 0.05 \\
\hline \multicolumn{5}{|c|}{ If male attacked - responses only $(n=79)$} \\
\hline$T T+A D$ & 0.35 & 4 & 0.00 & 0.51 \\
\hline$T T+A D+T T * A D$ & 0.36 & 6 & 3.35 & 0.09 \\
\hline$T T+T C$ & 0.29 & 4 & 3.37 & 0.09 \\
\hline$T T+R C$ & 0.32 & 5 & 4.30 & 0.06 \\
\hline$T T+F P+A D+F P * A D$ & 0.35 & 6 & 4.60 & 0.05 \\
\hline$T T$ & 0.24 & 3 & 4.82 & 0.05 \\
\hline \multicolumn{5}{|c|}{ Total number of male attacks - responses only $(n=79)$} \\
\hline$T T+A D+T T * A D$ & 0.25 & 7 & 0.00 & 0.65 \\
\hline$T T+A D$ & 0.18 & 5 & 2.10 & 0.23 \\
\hline$T T+F P+A D+F P * A D$ & 0.20 & 7 & 4.87 & 0.06 \\
\hline
\end{tabular}

${ }^{a}$ Difference in AICc units between a given model and the top-ranking model.

b Probability that a given model is the best-approximating model of the models in the set.

c A posteriori model. 
Table 3

Model-averaged estimates and 95\% confidence intervals for treatment effects of male barred owl residents presented with northern spotted owl treatment (BAOW/SPOW) and male northern spotted owl residents presented with barred owl treatment (SPOW/BAOW) relative to trials in which northern spotted owl residents were presented with the northern spotted owl treatment.

\begin{tabular}{|c|c|c|c|c|}
\hline \multirow[t]{2}{*}{ Analysis } & \multicolumn{2}{|c|}{ BAOW/SPOW treatment } & \multicolumn{2}{|c|}{$\underline{\text { SPOW/BAOW treatment }}$} \\
\hline & Estimate & $95 \% \mathrm{CI}$ & Estimate & $95 \% \mathrm{CI}$ \\
\hline \multicolumn{5}{|l|}{ All trials $(n=126)$} \\
\hline Whether response detected & -0.47 & $-1.09,0.16$ & -0.11 & $-0.69,0.48$ \\
\hline \multicolumn{5}{|l|}{ Response trials $(n=79)$} \\
\hline Calling frequency & 1.04 & $0.01,2.08$ & -1.22 & $-2.33,-0.11$ \\
\hline Whether attack occurred & 1.42 & $0.25,2.59$ & -2.02 & $-3.73,-0.31$ \\
\hline Total number of attacks & -1.00 & $-3.13,1.13$ & -2.65 & $-5.84,0.54$ \\
\hline
\end{tabular}

Given that a male response was detected, the three top-ranked generalized linear models predicting the total number of male attacks per trial ( $n=79$ trials) included the $A D$ variable, which indicated that the number of attacks decreased as the summer progressed $(\widehat{\bar{\beta}}=-0.03,95 \% \mathrm{CI}=-0.08,0.01$; cumulative Akaike weight of 0.94; Tables 2 and 3). Model-averaged parameter estimates for TT suggested that there was no difference between barred and northern spotted owls residents receiving the interspecific playback treatments relative to northern spotted owl residents responding to the northern spotted owl treatment (Table 3).

Accelerometer data were collected from eight strikes directed at the northern spotted owl taxidermy mount by five male barred owls and 14 strikes directed at the northern spotted owl mount by two male northern spotted owls. Based on these data, $H I C_{15}$ estimates ranged from 35.80 to $83.33(\bar{x}=57.42,95 \% \mathrm{CI}=45.86,68.98)$ for barred owl strikes and 26.92 to 318.24 ( $\bar{x}=113.61,95 \%$ $\mathrm{CI}=74.04,153.18)$ for northern spotted owl strikes, indicating that northern spotted owls struck the taxidermy mounts with an increased capacity to cause head injury compared to barred owls.

\section{Discussion}

We observed both intra- and interspecific responses by male resident northern spotted and barred owls. Interspecific interactions occurred less frequently than did intraspecific interactions between northern spotted owls alone. However, when interspecific interactions occurred, barred owls had a higher calling frequency and a larger number of trials resulting in a strike relative to northern spotted owls, indicating that barred owls likely would act as the dominant species during agonistic encounters with northern spotted owls.

\subsection{Acquiescence versus exclusion hypotheses}

In general, the Acquiescence Hypothesis was largely supported because northern spotted owls called less often, attacked less frequently, and attacked fewer times overall when presented with the barred owl treatment than when they received the northern spotted owl treatment (Table 4). However, similar response frequencies between treatments and an increased capacity for northern spotted owl strikes to cause head injury did not meet predictions of the Acquiescence Hypothesis. The Acquiescence Hypothesis has also been partially supported by previous studies where northern spotted owls responded less often to broadcast calls from conspecifics after barred owl calls were broadcast in an area (Crozier et al., 2006) and northern spotted owls had lower detection probabilities in the presence of barred owls (Bailey et al., 2009; Olson et al., 2005). Crozier et al. (2006) also found that northern spotted owls responded less often in areas with higher barred owl density, suggesting that northern spotted owls may exhibit shifts in vocal behavior in the presence of barred owls.

We found mixed support for the Exclusion Hypothesis (Table 4). Barred owls gave more aggressive calls and struck the northern spotted owl model more frequently than northern spotted owls did, both of which agreed with the Exclusion Hypothesis. However, male barred owls responded less frequently and their strikes exhibited a reduced capacity to cause injury from blunt force, which contradicted our predictions. Despite general support for the prediction that intraspecific competition is generally stronger than interspecific competition (Connell, 1983), the reduced frequency of responses by barred owls receiving the northern spotted owl treatment was surprising because of the perception held by researchers that barred owls are more aggressive than northern spotted owls (Dark et al., 1998; Herter and Hicks, 2000). Although Wiens et al. (2011) also found that barred owls responded less frequently to spotted owl calls than spotted owls, the lower response frequency by barred owls we observed may have been influenced by the fact that $84 \%$ of trials in northern spotted owl territories were set-up within $100 \mathrm{~m}$ of daytime locations while $66 \%$ of trials in barred owl territories were at daytime locations. This difference in trial locations between treatments could have negatively biased results because residents would likely respond to treatments when the trial site was closer to their territory center.

Dominance in interspecific interactions can be strongly influenced by body mass between competing owl species (Martínez et al., 2008), and the results of our study were in keeping with this expectation because male barred owls (the larger species) gave

Table 4

Relative support for the exclusion and acquiescence hypotheses based on model-averaged treatment type (TT) effects on whether responses occurred, aggressive calling frequency, whether an attack occurred, and the total number of attacks. (+) indicates weak support for the hypothesis (i.e., 95\% CI for (TT) barely overlapped zero), (++) indicates strong support for the hypothesis (i.e., the 95\% confidence interval for (TT) did not overlap zero), (0) indicates no substantial difference among treatments (i.e., $95 \% \mathrm{CI}$ largely overlapped 0 ), ( - ) indicates weak evidence against the hypothesis (i.e., 95\% CI for (TT) barely overlapped zero).

\begin{tabular}{|c|c|c|}
\hline Response variable & $\begin{array}{l}\text { Exclusion hypothesis } \\
\text { BAOW/SPOW }^{\mathrm{a}} \text { treatment }\end{array}$ & $\begin{array}{l}\text { Acquiescence hypothesis } \\
\text { SPOW/BAOW }{ }^{\mathrm{a}} \text { treatment }\end{array}$ \\
\hline Response & - & 0 \\
\hline Attacks & ++ & ++ \\
\hline Total number of attacks & - & + \\
\hline
\end{tabular}

${ }^{\text {a }}$ For each treatment type the first acronym represents the resident species followed by the playback species that was presented to the resident species. 
aggressive calls more frequently and attacked northern spotted owl mounts in more trials than did the smaller northern spotted owls. Leskiw and Gutiérrez's (1998) suggestion that such attacks could result in northern spotted owl mortality may explain the observed reduction of northern spotted owl survival in the presence of barred owls (Anthony et al., 2006). Effects of even occasional intraguild predation can extend beyond the immediate individual effects to the population and community levels by reducing fitness due to predator avoidance, changing foraging behavior, and reducing the ability of individuals to find mates and to hold territories (Hakkarainen and Korpimäki, 1996; Lima and Dill, 1990; Sergio et al., 2007). Mikkola (1976) found that smaller owls were occasionally in diets of larger owls, but rarely the reverse. Furthermore, generalist owls engaged in intraguild predation far more frequently than did specialists, presumably because they could gain energetic benefits from the consumption of a competitor (Mikkola, 1976). Fewer physical responses to barred owls by northern spotted owls may ultimately be a result of greater trophic specialization by this species or may have evolved through reduction of interspecific physical altercations to avoid potential predation by larger owls.

Encounters between barred and northern spotted owls appear to have three potential outcomes with northern spotted owls (1) acquiescing and ultimately being displaced, (2) responding aggressively and maintaining possession of their territories, or (3) responding aggressively and being either injured or killed during the encounter. The interactions between barred and northern spotted owls observed in this study appear to demonstrate elements of both the Acquiescence and Exclusion Hypotheses and may ultimately depend on individual variation. However, the apparent reduction in northern spotted owl populations in some areas of co-occurrence (Anthony et al., 2006) suggests that barred owls are assuming the dominant role during interspecific interactions and may effectively outcompete their congeners in areas of sympatry.

\subsection{Potential for injury from attacks}

Northern spotted owls appear to have a greater potential to cause trauma from blunt force during strikes than do barred owls. Van Lanen (2010) used a pendulum experiment with representative masses for these two species to determine the relative effects of attacker mass and velocity on $\mathrm{HIC}_{15}$ values resulting from collisions. This work demonstrated that attacker flight velocity immediately prior to impact has a larger effect on the resultant head acceleration following a strike than attacker body mass. As a smaller and presumably more maneuverable species, northern spotted owls are likely able to reach greater flight velocities than barred owls in the confined understory of the forest types where trials took place. Our findings contradict both the Exclusion and Acquiescence Hypotheses which predicted that strikes from the larger barred owl would result in greater $H_{I} C_{15}$ values. However, it is still unclear whether the $H_{1} C_{15}$ values observed in this study could prove lethal for either northern spotted or barred owls, if northern spotted and barred owls can tolerate different magnitudes of blunt force, or whether there is a threshold beyond which injuries will result regardless of the magnitude of blunt force.

Our measure of blunt force failed to account for potential injury due to punctures or lacerations inflicted by talons. Talon grip force of raptors increases exponentially with body mass (Ward et al., 2002); therefore, it is possible that injuries resulting from puncture wounds and lacerations may allow barred owls to inflict mortal wounds.

\subsection{Competitive exclusion of northern spotted owls?}

The intensity of vocal and physical interactions between barred and northern spotted owls estimated in this study suggests that barred owls act as dominants when these two species engage in territorial conflict. Amarasekare (2002) suggested that exclusion of a native species by an invasive species is likely if the invasive species exerts dominance in interspecific interference competition and if it is superior at exploiting resources. As generalist predators, barred owls may exist at higher densities than northern spotted owls (Hamer et al., 2007), and may be superior at resource exploitation (Hamer et al., 2001), which could ultimately result in exclusion of northern spotted owls.

Although displacement of northern spotted owls by barred owls appears to be the most likely outcome, viable populations of northern spotted owls may persist under a number of scenarios. Responses to playbacks were highly variable and indicated a substantial degree of behavioral plasticity among individuals, which might result from heritable genetic differences. Future studies of this and other systems should attempt to identify and isolate whether behavioral plasticity results from genetic differences or is influenced by environmental factors (e.g., habitat and prey conditions) and individual characteristics (e.g., age, breeding status). If aggression is a heritable trait, intense intraspecific competition among northern spotted owls for high-quality habitat could potentially result in aggressive individuals occupying the most productive territories (Andrén, 1990; Fretwell and Lucas, 1970; Klomp, 1972). By preserving high-quality northern spotted owl habitat, these aggressive individuals may be at a selective advantage, assuming residents of these high-quality sites produce offspring that are subsequently recruited into the population. Changes in the frequency of heritable traits for aggression within northern spotted owl populations could result in a positive shift in the frequency that northern spotted owls retain their territories in the presence of barred owls.

Additionally, individual behavioral shifts as a result of learning may mitigate some risk to northern spotted owls. Predator avoidance usually occurs in the form of temporal segregation, risksensitive habitat selection, spatial avoidance, and/or short-term behavioral avoidance (Sergio and Hiraldo, 2008). Temporal segregation is not plausible because these two species are primarily nocturnal. However, these two species do exhibit some differences in habitat preference (Hamer et al., 2007; Herter and Hicks, 2000; Pearson and Livezey, 2003), making risk-sensitive habitat selection and spatial avoidance possible. Also, northern spotted owls may learn to exhibit short-term behavioral avoidance to reduce the frequency of agonistic interactions with barred owls. Some evidence suggests that this might already be occurring in some areas of co-existence, with northern spotted owls calling less frequently in the presence of barred owls and subsequently decreasing the rate at which barred owls detect these individuals (Crozier et al., 2006).

Interspecific interference competition is likely occurring in this system with barred owls assuming the role of dominants during interactions. This suggests that long-term persistence of viable northern spotted owl populations will likely depend upon a variety of factors including behavioral shifts by northern spotted owls to reduce competition in the presence of barred owls over time, plasticity in territorial aggression by northern spotted owls, the existence of refugia within the current northern spotted owl's range affording this species habitat-mediated or distance-sensitive avoidance of competitors, or the active management of barred owl populations to conserve northern spotted owls.

\section{Acknowledgements}

We thank Drs. Ken Burnham, Barry Noon, David Anderson, Phillip Chapman, and Brian Jones for their advice regarding experimental design and analyses. Tom Ferraro, of National Instruments, wrote a Lab View software application specifically for this research. 
We also thank the Hoopa Tribe, Green Diamond Resource Company, and Redwood National and State Parks for allowing us to conduct this research on their lands. Their personnel, particularly Dr. Lowell Diller, Keith Hamm, Brian Yost, Kristin Schmidt, Laura Weisel, and Mark Higley were of great assistance in facilitating access and providing owl location information. Field assistants Shannon Wadham and Amon Armstrong assisted with data collection in the field. Funding for the project was provided by the U.S.D.A. Forest Service Region 5 Office and by the Cooper Ornithological Society. Three anonymous reviewers provided helpful comments and suggestions which improved this manuscript.

\section{References}

Amarasekare, P., 2002. Interference competition and species coexistence. Proceedings of the Royal Society of London B 269, 2541-2550.

Andrén, H., 1990. Despotic distribution, unequal reproductive success and population regulation in the jay Garrulus glandarius L.. Ecology 71, 1796-1803.

Anthony, R.G., Forsman, E.D., Franklin, A.B., Anderson, D.R., Burnham, K.P., White, G.C., Schwarz, C.J., Nichols, J.D., Hines, J.E., Olson, G.S., Ackers, S.H., Andrews, L.S., Biswell, B.L., Carlson, P.C., Diller, L.V., Dugger, K.M., Fehring, K.E., Fleming, T.L, Gerhardt, R.P., Gremel, S.A., Gutiérrez, R.J., Happe, P.J., Herter, D.R., Higley, J.M., Horn, R.B., Irwin, L.L., Loschl, P.J., Reid, J.A., Sovern, S.G., 2006. Status and trends in demography of northern spotted owls, 1985-2003. Wildlife Monographs $163,1-48$.

Bailey, L.L., Reid, J.A., Forsman, E.D., Nichols, J.D., 2009. Modeling co-occurrence of northern spotted and barred owls: accounting for detection probability differences. Biological Conservation 142, 2983-2989.

Beckwith, J.G., Chu, J.J., Greenwald, R.M., 2007. Validation of a noninvasive system for measuring head acceleration for use during boxing competition. Journal of Applied Biomechanics 23, 238-244.

Buchanan, J.B., Gutiérrez, R.J., Anthony, R.G., Cullinan, T., Diller, L.V., Forsman, E.D., Franklin, A.B., 2007. A synopsis of suggested approaches to address potential competitive interactions between barred owls (Strix varia) and spotted owls (S. occidentalis). Biological Invasion 9, 679-691.

Burnham, K.P., Anderson, D.R., 2002. Model Selection and Multimodel Inference: A Practical Information-Theoretical Approach, second ed. Springer-Verlag, New York.

Connell, J.H., 1983. On the prevalence and relative importance of interspecific competition: evidence from field experiments. American Naturalist 122, 661696.

Crozier, M.L., Seamans, M.E., Gutiérrez, R.J., Loschl, P.J., Horn, R.B., Sovern, S.G. Forsman, E.D., 2006. Does the presence of barred owls suppress the calling behavior of spotted owls? Condor 108, 760-769.

Dark, S.J., Guiterrez, R.J., Gould Jr., G.I., 1998. The barred owl (Strix varia) invasion in California. Auk 115, 50-56.

Diller, L.V., Thome, D.M., 1999. Population density of northern spotted owls in managed young-growth forests in coastal Northern California. Journal of Raptor Research 33, 275-286.

Dunbar, D.L., Booth, B.P., Forsman, E.D., Hetherington, A.E., Wilson, D.J., 1991. Status of the spotted owl, Strix occidentalis, and barred owl, Strix varia, in southwestern British Columbia. Canadian Field-Naturalist 105, 464-468.

Forsman, E.D., Meslow, C.E., Wight, H.M., 1984. Distribution and biology of the spotted owl in Oregon. Wildlife Monographs 87, 1-64.

Franklin, A.B., Anderson, D.R., Forsman, E.D., Burnham, K.P., Wagner, F.W., 1996. Methods for collecting and analyzing demographic data on the northern spotted owl. Studies in Avian Biology 17, 12-20.

Franklin, A.B., Anderson, D.R., Gutiérrez, R.J., Burnham, K.P., 2000. Climate, habitat quality, and fitness in northern spotted owl populations in Northwestern California. Ecological Monographs 70, 539-590.

Franklin, A.B., Carlson, P.C., Rockweit, J.T., Canter, A.N., Roberts, A., Hanks, T., Lewicki, K., Schielke, B., Wilson, K., 2009. Monitoring the Population Ecology of Spotted Owls (Strix occidentalis caurina) in Northwestern California: Annual Results, 2008. Annual Progress Report to Region 5, USDA Forest Service.

Freeman, P.L., 1999. Spectrogram Analysis of Variation in Male Barred Owl Vocalizations. M.S. Thesis, North Dakota State University, Fargo, ND, USA

Fretwell, S.D., Lucas Jr., H.L., 1970. On territorial behavior and other factors influencing habitat distribution in birds. I. Theoretical development. Acta Biotheoretica 19, 16-36.

Ganey, J.L., 1990. Calling behavior of spotted owls in Northern Arizona. Condor 92, 485-490.

Gutiérrez, R.J., Cody, M., Courtney, S., Franklin, A.B., 2007. The invasion of barred owls and its potential effect on the spotted owl: a conservation conundrum. Biological Invasions 9, 181-196.

Gutiérrez, R.J., Franklin, A.B., LaHaye, W.A., 1995. Spotted owl (Strix occidentalis). In: Poole, A., Gill, F. (Eds.), The Birds of North America, No. 179. The Academy of Natural Sciences and The American Ornithologists' Union, Washington, DC, USA.

Hakkarainen, H., Korpimäki, E., 1996. Competitive and predatory interactions among raptors: an observational and experimental study. Ecology 77, 1134-1142.

Hamer, T.E., Forsman, E.D., Fuchs, A.D., Walters, M.L., 1994. Hybridization between barred and spotted owls. Auk 111, 487-492.
Hamer, T.E., Hays, D.L., Senger, C.M., Forsman, E.D., 2001. Diets of northern barred owls and northern spotted owls in an area of sympatry. Journal of Raptor Research 35, 221-227.

Hamer, T.E., Forsman, E.D., Glenn, E.M., 2007. Home range attributes and habitat selection of barred owls and spotted owls in an area of sympatry. Condor 109, 750-768.

Herter, D.R., Hicks, L.L., 2000. Barred owl and spotted owl populations and habitat in the central Cascade Range of Washington. Journal of Raptor Research 34, 279286.

Hyman, J., Hughes, M., Searcy, W.A., Nowicki, S., 2004. Individual variation in the strength of territory defense in male song sparrows: correlates of age, territory tenure, and neighbor aggressiveness. Behaviour 141, 15-27.

Jackson, K.E., Fasanell, E.L., Boitnott, R.L., McEntire, J.M., Lewis, A., 2002. Occupant Responses in a Full-scall Crash Test of the Sikorsky ACAP Helicopter. NASA/TM2002-211733 ARL-TR-2735.

Kelly, E.G., Forsman, E.D., Anthony, R.G., 2003. Are barred owls displacing spotted owls? Condor 105, 45-53.

Klomp, H., 1972. Regulation of the size of bird populations by means of territorial behavior. Netherlands Journal of Zoology 22, 456-488.

Leskiw, T., Gutiérrez, R.J., 1998. Possible predation of a spotted owl by a barred owl. Western Birds 29, 225-226.

Lima, S.L., Dill, L.M., 1990. Behavioral decisions made under the risk of predation: a review and prospectus. Canadian Journal of Zoology 68, 619-640.

Livezey, K.B., 2009. Range expansion of barred owls, part I: chronology and distribution. American Midland Naturalist 161, 49-56.

Martínez, J.E., Martínez, J.A., Zuberogoitia, I., Zabala, J., Redpath, S.M., Calvo, J.F., 2008. The effect of intra- and interspecific interactions on the large-scale distribution of cliff-nesting raptors. Ornis Fennica 85, 13-21.

Mazur, K.M., James, P.C., 2000. Barred owl (Strix varia). In: Poole, A., Gill, F. (Eds.) The Birds of North America, No. 508. The Academy of Natural Sciences and The American Ornithologists' Union, Washington, DC, USA.

McGarigal, K., Fraser, J.D., 1985. Barred owl responses to recorded vocalizations Condor 87, 552-553.

Mikkola, H., 1976. Owls killing and killed by other owls and raptors in Europe. British Birds 69, 144-154.

NOAA Earth System Research Laboratory (ESRL), 2008. 325 Broadway, Boulder, Colorado 80305.

Odom, K.J., Mennill, D.J., 2010. A quantitative description of the vocalizations and vocal activity of the barred owl. Condor 120, 549-560.

Olson, G.S., Anthony, R.G., Forsman, E.D., Loschl, P.J., Reid, J.A., Dugger, K.M., Glenn, E.M., Ripple, W.J., 2005. Modeling of site occupancy dynamics for northern spotted owls, with emphasis on the effects of barred owls. Journal of Wildlife Management 69, 918-932.

Pearson, R.R., Livezey, K.B., 2003. Distribution, numbers, and site characteristics of spotted owls and barred owls in the Cascade Mountains of Washington. Journal of Raptor Research 37, 265-276.

Pfister, B.L. Chickola, L, Smith, D.H, 2009. Head motions while riding rolle coasters: Implications for brain injury. American Journal of Forensic Medicine and Pathology 30, 339-345.

Polis, G.A., Myers, C.A., Holt, R.D., 1989. The ecology and evolution of intraguild predation: potential competitors that eat each other. Annual Review of Ecological Systems 20, 297-330.

Reid, J.A., Horn, R.B., Forsman, E.D., 1999. Detection rates of spotted owls based on acoustic-lure and live-lure surveys. Wildlife Society Bulletin 27, 986-990.

SAS Institute, 2003. SAS/STAT User's Guide. Release 9.1. SAS Institute, Cary, North Carolina, USA.

Schmidt, K., 2004. Northern Spotted Owl Monitoring and Inventory, Redwood National and State Parks 2003 Annual Report. Redwood National and State Parks, Orick, California.

Sergio, F., Marchesi, L., Pedrini, P., 2003. Spatial refugia and the coexistence of a diurnal raptor with its intraguild owl predator. Journal of Animal Ecology 72, 232-245.

Sergio, F., Marchesi, L., Pedrini, P., Penteriani, V., 2007. Coexistence of a generalist owl with its intraguild predator: distance-sensitive or habitat-mediated avoidance? Animal Behaviour 74, 1607-1616.

Sergio, F., Hiraldo, F., 2008. Intraguild predation in raptor assemblages: a review. Ibis $150,132-145$.

Sergio, F., Blas, J., Hiraldo, F., 2009. Predictors of floater status in a long-lived bird: a cross-sectional and longitudinal test of hypotheses. Journal of Animal Ecology $78,109-118$.

Taylor, A.L., Forsman, E.D., 1976. Recent range extensions of the barred owl in Western North American, including the first records for Oregon. Condor 78, 560-561.

Ting, T.F., 1998. The Thermal Environment of Northern Spotted Owls in Northwestern California: Possible Explanations for Use of Interior Old Growth and Coastal Early Successional Stage Forest. M.S. Thesis, Humboldt State University, Arcata, CA, USA.

Turchi, R., Altenhof, W., Kapoor, T., Howard, A., 2004. An investigation into the head and neck injury potential of three-year-old children in forward and rearward facing child safety seats. International Journal of Crashworthiness 9, 419-431.

US Fish and Wildlife Service, 1990. 50 CFR Part 17 Endangered and threatened wildlife and plants; determination of threatened status for the northern spotted owl; final rule. Federal Register 55, 26114-26194.

US Department of Agriculture Forest Service (USFS) and Bureau of Land Management (BLM), 1994. Final Supplemental Environmental Impact Statement on Management of Habitat for Late-successional and Old-growth 
Forest within the Range of the Northern Spotted Owl. USDA Forest Service, Portland, Oregon, and BLM, Moscow, Idaho.

Van Lanen, N.J., 2010. Out with the Old, in with the New? Investigating Competition between Barred Owls (Strix varia) and Northern Spotted Owls (Strix occidentalis caurina) in Northwestern California with a Playback Experiment. M.S. Thesis, Colorado State University, Fort Collins, CO, USA.

Waldo, S.L., 2002. Song Discrimination of Neighbors and Strangers by Male Territorial Northern Spotted Owls (Strix occidentalis caurina). M.S. Thesis, Humboldt State University, Arcata, CA, USA.
Ward, A.B., Weigl, P.D., Conroy, R.M., 2002. Functional morphology of raptor hindlimbs: implications for resource partitioning. Auk 119, 1052-1063.

Wiens, J.D., Anthony, R.G., Forsman, E.D., 2011. Barred owl occupancy surveys within the range of the northern spotted owl. Journal of Wildlife Management 75 (3), 531-538.

Zuberogoitia, I., Martínez, J.E., Zabala, J., Martínez, J.A., Azkona, A., Castillo, I., Hidalgo, S., 2008. Social interactions between two owl species sometimes associated with intraguild predation. Ardea 96, 109-113. 